\title{
PROSTHETICS AND ORTHOTICS IN REHABILITATION: A SHORT COMMUNICATION
}

\section{Akshay Kumar*}

Prosthetist \& Orthotist, Department of Prosthetics \& Orthotics, Composite Regional Centre for Persons with Disabilities, Kozhikode, Kerala, India. ${ }^{*}$ Corresponding Author

Vinita Centre, Kozhikode, Kerala, India.

ABSTRACT Prosthetics and orthotics is a field of health care and rehabilitation, which deals with external devices to the patients either to replace the missing body parts or to support the weakened body parts. The main purpose is to disseminate knowledge and awareness about prosthetic and orthotic science among professionals working in the field of health care and rehabilitation. This can increase patient prosthetic and orthotic care services across the world and wellbeing.an online search carried out to find out the various perspective of prosthetics and orthotics as follows definition, history, demography, and role of Prosthetist and orthotist in disability optimization. Early identification and appropriate prosthetic and orthotic intervention can bring hope and independency in the patient to lead a normal life.

\section{KEYWORDS :}

Introduction:

Prosthetics and orthotics science is the branch of health care and rehabilitation that deals with artificial limb/prosthesis for amputees and supportive devices (Orthosis) for the person having orthopedic, musculoskeletal, or neurologic disorders ("What is Prosthetics and Orthotics?," n.d.) .

A prosthesis is an artificial device that replaces the missing body parts of the human body and reflects the near-normal color, texture, and function of the sound limb of the human body with technological advancement and an Orthosis is a supportive device that acts on the weakened body to assist, restrict, support, immobilize, align, etc. the affected body parts ("Difference Between Orthotics \& Prosthetics | Excel,"n.d.).

The professionals, who assess, evaluate, prescribe, fabricate, and treat the patient resulting from illness, disorder, or disabilities including orthopedic, neurologic, and limb loss are known as Prosthetist \& Orthotist ("What is an orthotist/prosthetist? - The Australian Orthotic Prosthetic Association Ltd. (AOPA)," n.d.).

Rehabilitation council of India is a parliamentary enacted body that regulates the rehabilitation professionals across the country and maintains a central rehabilitation register for the qualified professionals working in the field of rehabilitation. And prosthetist and orthotist are categorized under locomotor rehabilitation professionals. Practicing the assessment, prescription, and fitment of prosthesis and orthosis and assistive devices is a punishable offense under various Indian panel codes("Rehabilitation Council of India," n.d.).

\section{History:}

The shreds of evidence show that the earliest possible prosthesis was made for the cosmetic purpose of the missing body parts for the soldiers who lost their limb in war. Evidence of carbon dating proves its ages of $2500 \mathrm{BC}$. There are some more ancient records of using the prosthetic hand in Rigveda by queen wheeplashsa. Till the $19^{\text {th }}$ century, the skill was not much exposed worldwide and was limited to the small workshops. Post World War I nations of prosthetic firms started gathering and the US government supported that move, which was then lagging Europe. AOPA (American prosthetic and Orthotic Association) formed with an aim to develop ethical standards and shaping relations with rehabilitation practitioners. The minimum standard was set for practitioners post-formation of $\mathrm{ABC}$ (American Board for certification in
Prosthetic and Orthotic).it was world war II post that many research project started to develop new efficient designs in prosthetic and orthotic due to increased demand of devices (Prosthesis/orthosis) due to more casualties. Also, the polio epidemic in the mid of the nineteenth century increases the need and demand for orthotic research for the user-centric. Till now in $21^{\text {st }}$-century innovation in the prosthetic and orthotic field is going on and the efficiency of prosthetic and orthotic devices increased vastly due to sophisticated products like microprocessor prosthetic knee, foot, and orthotic joints and increased efficiency("A History Of Prosthetics And Orthotics," n.d.).

\section{Demography:}

Locomotor disability is an important public concern and restricts the individual to lead a normal life. The loss of movement fully or partially affects the individual's family, social, and economic condition. World Health Organization (WHO) states that about $15 \%$ of the world population estimated to be with a disability with measurable impact in low-income countries like India. Around 785-795 million population across the world above the age of 15 and older supposed to be living with a disability. The NSSO(National Sample Survey Organisation) estimates that nearly 2\% population are disabled and prevalence for locomotor disability is highest among all comprising nearly $20 \%$ of the total disabled with the rate of 1046 and 906 per 1 lakh population in rural and urban area respectively(Mishra et al., 2019).

\section{Role in rehabilitation:}

The need for orthotic \& prosthetic services is most essential for locomotors differently able to achieve independent movement and mobility as well as to enjoy their human rights and equal opportunity as others in society. As in the Indian context, the RPwD, Act 2016 and UNCRPD ratification obligate the government to ensure access to high-quality affordable prosthetic \& orthotic devices and services to differently able to strengthen their status in society(Com, 2017b).

To fulfill the requirement of service delivery, a country requires 5 to 10 Orthotics \& prosthetics clinicians per million populations. However, in low-income countries like India no of professionals is low as per 1 million populations, cause poor and insufficient service delivery to differently able, which hampers their personal dignity and national productivity as well. On an average $300-600$ patients can be assisted to 
complete service including the first provision to follow-up and maintenance of prosthetic and orthotic devices. The number may vary upon the complexity and type of treatment (Com, 2017a).

\section{Conclusion:}

Disability optimization and eradication can be done through the earliest possible rehabilitative action taken can minimize its impact and increase individual social participation. Early detection as well as appropriate rehabilitative intervention is imperative to promote and enhance health conditions, increase the accessibility to public places, make them independent with equal opportunity, improve economic and social status, and participation in nation-building.

\section{REFERENCES:}

1. A History Of Prosthetics And Orthotics. (n.d.). Retrieved May 6, 2020, from https://www.llop.com/history-orthotic-prosthetics/

2. Com, I. (2017 $\alpha$ ). Part 2: IMPLEMENTATION MANUAL Technical contribution: STANDARDS FOR PROSTHETICS AND ORTHOTICS - PART 2. IMPLEMENTATION MANUAL WHO standards for prosthetics and orthotics Contents: Part 1. Standards; Part 2. Implementation manual. Retrieved from http://apps.who.int/bookorders.

3. Com, I. standards for prosthetics and orthotics part-1., (2017).

4. Difference Between Orthotics \& Prosthetics | Excel. (n.d.). Retrieved May 6, 2020, from https://www.excel-prosthetics.com/2018/08/07/prosthetics-vsorthotics-whats-difference/

5. Mishra, K., Siddharth, V., Bhardwaj, P., Elhence, A., Jalan, D., Raghav, P. \& Mahmood, S. (2019). The prevalence pattern of locomotor disability and its impact on mobility, self-care, and interpersonal skills in rural areas of Jodhpur District. Nigerian Medical Journal, 60(3), 156. https:// doi. org/ 10.4103/ nmj.nmj 14417

6. Rehabilitation Council of India. (n.d.). Retrieved May 7, 2020, from http://www.rehabcouncil.nic.in/default.aspx

7. What is an orthotist/prosthetist? - The Australian Orthotic Prosthetic Association Ltd. (AOPA). (n.d.). Retrieved May 6, 2020, from https:// www. aopa.org.au/careers/what-is-an-orthotistprosthetist-2

8. What is Prosthetics and Orthotics? (n.d.). Retrieved May 6, 2020, from https:// mspo.gatech.edu/prosthetics-orthotics/ 